The Economic Impact of Demand-Response Programs on Power Systems. A survey of the State of the Art.

Adela Conchado

Pedro Linares 


\title{
The economic impact of demand-response programs on power systems. A survey of the state of the art
}

\author{
Adela Conchado, Pedro Linares
}

Instituto de Investigación Tecnológica, Universidad Pontificia Comillas

\begin{abstract}
Demand Response (DR) programs, which aim to reduce electricity consumption in times of high energy cost or network constraints by allowing customers to respond to price or quantity signals, are becoming very popular in many electricity systems, frequently associated to smart-grid developments. These programs could entail significant benefits for power systems and the society as a whole. Assessing the magnitude of these benefits is crucial to determine their convenience, especially when there are non negligible costs associated to their implementation (if advanced metering infrastructure or control technologies are needed). Quantifying DR benefits requires first to estimate the changes in demand patterns that can potentially be achieved and then to evaluate the effects of those changes on the complex behavior of power systems, neither of these analyses being trivial. This paper presents a survey of the state of the art of these assessments.
\end{abstract}

Keywords demand response, power systems, benefits, cost-benefit analysis, survey

\section{Introduction}

In the present energy context, in which growing concerns on environmental sustainability and security of supply need to be tackled as cost-effectively as possible, demand side management can play an important role (IEA, 2008; EC, 2005). In the case of electricity, given that its cost and environmental impact vary over time, consuming more efficiently implies not only consuming less, but also managing consumption in time. Tools aiming to promote a more efficient distribution of electricity demand in time constitute what is known as Demand Response (DR). In essence, DR programs consist in providing incentives to consumers to get a reduction in demand in times of high energy cost or network constraints. In most cases, this would imply shifting some consumption from peak hours to off-peak hours. 
Although DR is not a new concept, it has been gaining interest recently, as power systems become more congested, smart grids develop, and the penetration of renewable energy increases. While most DR programs in past years have consisted on interruptible or curtailable services from large customers, nowadays the development of smart meters, home automation and advanced communication and control technologies enables more sophisticated forms of DR even at the household level, with domestic customers being able to adapt demand at their discretion in response to time-varying price signals.

The current interest in DR is materialized in numerous research projects (GAD (www.proyectogad.es) in Spain, Smart-A (www.smart-a.org) and ADDRESS (www.addressfp7.org) in Europe, Demand Response Research Center (http://drrc.lbl.gov) in the USA and IEA Demand Side Management Programme (www.ieadsm.org) internationally), trials and initiatives. Faruqui and Sergici (2009) presented a survey of the 15 most recent experiments with dynamic pricing at the household level. RRI (2008) reviewed the current status of DR in the USA, and Goldfine et al. (2008) the major developments in DR programs and initiatives. Some countries and regions have carried out studies to assess the costeffectiveness or potential for advanced metering and DR (e.g. FERC (2006) for the USA, NERA (2008) for Australia, Vasconcelos (2008) for the European Union, Navigant (2005) for Ontario (Canada)), and many countries have started deploying smart meters or have set roll-out targets, which will facilitate the implementation of DR programs and broaden their possibilities. In Europe, the penetration rate of smart meters is about $85 \%$ in Italy and $25 \%$ in France. UK, Spain, Ireland, the Netherlands, Norway and France have set deployment targets to achieve nearly $100 \%$ smart meter installation by 2020 (Faruqui et al., 2009).

DR programs can result in significant benefits for power systems (e.g. US DOE, 2006), but can also entail non negligible costs, especially if an advanced metering, communication or remote control infrastructure is put in place to facilitate automatic demand response. For this reason, assessing the benefits of DR is a necessary step to determine the interest of DR programs, both from the perspective of regulators and market agents.

However, the assessment of benefits a priori is not trivial: it is difficult to estimate how demand patterns would change, and understanding the effects of such changes on intrinsically complex power systems requires a thorough analysis. A range of studies have analyzed these effects both qualitatively and quantitatively, providing valuable insights and constituting a useful starting point for future studies.

The purpose of this paper is to present the state of the art of the analysis and assessment of the economic impacts of DR on power systems. Since the evaluation of implementation costs is not too complex, the focus will be on the evaluation of benefits.

After providing some background on DR in Section 2, the potential benefits of DR will be identified and described in Section 3, and the methodologies to quan- 
tify them that have been proposed in the literature will be reviewed in Section 4 . Throughout these sections, a special emphasis in providing useful references on the different topics will be made. The paper will finish in Section 5 with some conclusions about the current status of this topic and the issues that still need to be addressed.

\section{Background: categorization of demand response programs}

Being aware of the broad range of DR programs is important to understand the potential benefits that can be achieved and to put the variety of studies that have analyzed them in context. This section provides some background on the different designs and applications of DR programs.

There are many types of DR programs, which can be classified according to various criteria. Table 1 summarizes some classifications proposed in the literature. As shown in Table 1, DR can have reliability or economic purposes (RMI, 2006). Depending on the factor that triggers demand response, programs can be emergency-based or price-based (Faruqui and Hledik, 2007). With a similar meaning, but referring to the source of the trigger signal, they can be called system-led and market-led programs respectively (IEA, 2003). According to the type of signal provided (quantity or price), there are load response and price response programs (RMI, 2006). According to the method used to motivate DR, incentive-based programs or time-based rates can be distinguished (FERC, 2006; US DOE, 2006). Finally, there are direct load control programs, in which load reductions are controlled by a system operator, or passive load control programs, in which load reductions are controlled by customers (DTE Energy, 2007).

Table 1: Categorization of DR programs

\begin{tabular}{llll}
\hline Classification criteria & Dualities & & Source \\
\hline Purpose & Reliability & Economics & (RMI, 2006) \\
Trigger factor & Emergency-based & Price-based & (Faruqui and Hledik, 2007) \\
Origin of signal & System-led & Market-led & (IEA, 2003) \\
Type of signal & Load response & Price response & (RMI, 2006) \\
Motivation method & Incentive-based & Time-based rates & (FERC, 2006; US DOE, 2006) \\
Control & Direct load control & Passive load control & (DTE Energy, 2007) \\
\hline
\end{tabular}

To simplify, the whole range of DR programs may be reduced to two types, which correspond to each of the columns in Table 1. On the one hand, DR aiming to improve system reliability is generally implemented through emergency-based, system-led, load-response, incentive-based, direct-load control programs. On the other hand, DR aiming to reduce system costs is generally implemented through 
price-based, market-led, price-response (using time-based rates), passive load control programs.

Load response programs include direct load control, curtailable load, interruptible load and scheduled load. Price response programs include time-of-use (TOU) tariffs, dynamic pricing (such as critical-peak pricing (CPP) or real-time pricing (RTP)) and demand bidding (RMI, 2006). In general, in load response programs demand is remotely controlled upon conditions contracted with customers, while in price response programs, customers respond on their discretion to time-varying prices (Haney et al., 2009).

Some other factors that would influence the characteristics of DR programs, summarized in Table 2, are the following:

- The incentives to undertake DR and the program design differ significantly between liberalized market environments and centralized regulated environments (Borenstein et al., 2002; IEA, 2003).

- Similarly, it is important to consider if the promotion and financing of DR -or the installation of enabling technologies- is assumed by the regulator or is left to the initiative of market agents (NERA, 2008).

- The targeted segment of customers, from large industries to small commercial or domestic loads, is another relevant factor.

- Finally, the installation of enabling technologies critically determines DR options. For example, direct load control programs require remote control capabilities and real-time pricing requires an advanced metering infrastructure.

Table 2: Some other differentiating factors of DR programs

\begin{tabular}{|c|c|c|}
\hline Other criteria & Dualities & \\
\hline System/market structure & Vertically-integrated regulated system & Liberalized market \\
\hline Promotion and financing & By regulator & By market agents \\
\hline Targeted customers & $\begin{array}{l}\text { High-voltage } \\
\text { (industrial and large commercial) }\end{array}$ & $\begin{array}{l}\text { Low-voltage } \\
\text { (small commercial and domestic) }\end{array}$ \\
\hline Automation of response & $\begin{array}{l}\text { Manual response } \\
\text { (without enabling technologies) }\end{array}$ & $\begin{array}{l}\text { Automatic response } \\
\text { (with AMI and/or other smart devices) }\end{array}$ \\
\hline
\end{tabular}

\section{Potential benefits of demand response}

DR has a broad range of potential benefits. The benefits that will materialize in practice will depend on the purpose, design and performance of the DR program implemented, as well as on other factors such as the structure of the market/system and the enabling technologies in place. 
DR programs can have impacts on system operation, system expansion and market efficiency (the last only applicable in liberalized market environments). In this section, the potential benefits arising in those three aspects of power systems will be identified and described from a theoretical point of view (and summarized in Table 3). Some further considerations about the distribution of benefits among different agents and about smart metering will be pointed out as well.

\section{System operation}

DR programs where customers are able to respond to price signals that reflect to a certain extent real operational costs (generation and/or network costs) can achieve savings in system operation.

If prices reflect the cost of generation, part of the demand in times of high generation costs may be avoided or shifted to less expensive periods, resulting in some savings in the production of electricity.

If the cost of environmental impact is conveniently internalized in energy prices, the response of demand will also consider the impact on the environment (Spees and Lave, 2007). However, the change in net emissions will be very dependent on the generation mix. In systems in which marginal electricity in peak hours is produced from technologies emitting less $\mathrm{CO}_{2}$ than marginal technologies in off-peak hours (e.g. on-peak gas and off-peak coal, as occurs in many power systems), shifting some peak demand to off-peak could imply an increase in $\mathrm{CO}_{2}$ emissions, at least in the short-term (Holland and Mansur, 2007). Nevertheless, if not only shifting but also conservation effects from DR are taken into account, the overall emissions are likely to be reduced (Conchado and Linares, 2009b).

Another positive effect of DR on the operation of generation systems is facilitating the real-time balance of supply and demand, which is especially important when intermittent generation has large shares of production (Zibelman and Krapels, 2008). In fact, DR is considered as a major option to decrease problems caused by the variable and uncertain output of intermittent renewable sources (Kärkkäinen and Ikäheimo, 2009).

This contribution of DR to real-time balancing, coupled with the fact that DR can help to compensate supply shortages with load reductions in case of generation outages, may entail a reduction in the requirements of operating reserves for a certain level of short-term reliability of supply (or to increase short-term reliability of supply for a certain level of operating reserves) (Earle et al., 2009).

Regarding network operation, if network-driven DR actions are promoted (either through prices or through other agreed incentives), demand can respond to alleviate network constraints or to avoid outages in case of contingencies (Affonso et al., 2006). Moreover, DR can contribute to reduce lines losses (Shaw et al., 2009). DR programs can even provide ancillary services for electricity network system operators, such as voltage support, active/reactive power balance, fre- 
quency regulation and power factor correction (Crossley, 2008). All these effects on networks can mean an increase in network reliability and quality of supply.

\section{System expansion}

As already mentioned, DR can potentially reduce demand peaks, both local peaks in a particular area and system peaks.

At the local level, since networks are dimensioned for the highest expected demand, demand clipping can mean a reduction in the need for network reinforcement for a certain level of reliability (or an increase in long-term network reliability for the same level of investment).

At the system level, leveling the demand pattern reduces the need for installed capacity in peaking units. Moreover, it reduces the need of investment in capacity reserves (Braithwait et al. 2006) for a certain level of reliability of supply (or increases long-term reliability of supply for a certain level of capacity reserves).

Another effect of DR on the expansion of generation systems, which can be considered a benefit in countries where renewable energy is encouraged, is that it enables higher penetration of intermittent sources (by facilitating supply and demand balancing).

\section{Market efficiency}

In liberalized environments, market-driven DR programs, most frequently implemented in the form of time-varying tariffs, can allow an active participation of the demand side in the market and thereby achieve significant improvements in market efficiency.

This gives consumers the opportunity to maximize their utility by adjusting their demand in response to price signals. If price signals are accurate (in the sense that they reflect actual costs), only those consumers for whom consuming electricity at a certain time is worth at least as much as the cost it represents at that time would consume, resulting in a more efficient allocation of resources (EEI, 2006).

On the supply side, increasing the elasticity of demand would mitigate the generators' capacity to exercise market power (IEA, 2003: 54; Braithwait et al., 2006), which would also entail a reduction in the magnitude and number of price spikes (Kirschen, 2003; Borenstein et al., 2002).

Prices would also be moderated by the smoothing of the demand profile (IEA, 2003). However, it should be noticed that price reductions only represent wealth transfers from generators to consumers and not real savings for the society as a whole (Braithwait et al., 2006). 
DR may allow generators and retailers to reduce the cost of imbalances (IEA, 2003). Similarly, DR can also be seen as a way of hedging against price and production volatility (PLMA, 2002) and extreme system events difficult to predict (Violette et al., 2006a).

With the implementation of DR programs, retailers may increase their business opportunities and offer contracts to customers better suited to their demand profile. At the same time, consumers can benefit from a greater choice of contracts and save money if their consumption profile is favorable to the system (in the sense that demand is low in times of high cost).

\section{Summary of benefits}

Table 3 summarizes the potential benefits of DR that have been mentioned, categorized according to the activity of power systems where they originate. Notice that benefits are assigned to the activity where they originate regardless of the activity that finally receives them (the distribution of benefits among agents will be discussed in 3.5). In line with this, benefits included in Table 3 are only those that represent actual savings or gains in efficiency for the society as a whole, and not wealth transfers among agents.

Table 3: Potential benefits of DR

\begin{tabular}{|c|c|c|c|}
\hline & Operation & Expansion & Market* \\
\hline $\begin{array}{l}\text { Transmissior } \\
\text { and Distribu- } \\
\text { tion }\end{array}$ & 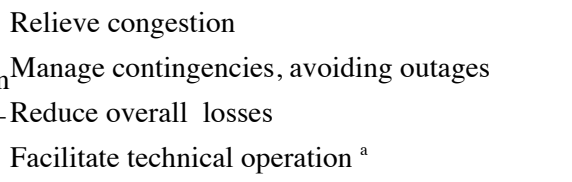 & $\begin{array}{l}\text { Defer investment } \\
\text { in network rein- } \\
\text { forcement or in- } \\
\text { crease long-term } \\
\text { network reliability }\end{array}$ & \\
\hline Generation & $\begin{array}{l}\text { Reduce energy generation in peak times: reduce } \\
\text { cost of energy and -possibly- emissions }{ }^{\text {b }} \\
\text { Facilitate balance of supply and demand (espe- } \\
\text { cially important with intermittent generation) } \\
\text { Reduce operating reserves requirements or } \\
\text { increase short-term reliability of supply }\end{array}$ & $\begin{array}{l}\text { Avoid investment } \\
\text { in peaking units } \\
\text { Reduce capacity } \\
\text { reserves require- } \\
\text { ments or increase } \\
\text { long-term reliabil- } \\
\text { ity of supply } \\
\text { Allow more pene- } \\
\text { tration of intermit- } \\
\text { tent renewable } \\
\text { sources }{ }^{c}\end{array}$ & $\begin{array}{l}\text { Reduce risk of im- } \\
\text { balances } \\
\text { Limit market pow- } \\
\text { er } \\
\text { Reduce price vola- } \\
\text { tility }\end{array}$ \\
\hline
\end{tabular}

Reduce risk of im- 


\begin{tabular}{|c|c|c|c|}
\hline \multirow{7}{*}{ Demand } & & \multirow{3}{*}{$\begin{array}{l}\text { Take investment } \\
\text { decisions with } \\
\text { greater awareness } \\
\text { of consumption } \\
\text { and cost }\end{array}$} & $\begin{array}{l}\text { New products, } \\
\text { more consumer } \\
\text { choice }\end{array}$ \\
\hline & $\begin{array}{l}\text { Consumers more aware of cost and consump- } \\
\text { tion, and even environmental impacts }\end{array}$ & & $\begin{array}{l}\text { Increase demand } \\
\text { elasticity }\end{array}$ \\
\hline & $\begin{array}{l}\text { Give consumers options to maximize their util- } \\
\text { ity: } \\
\text { opportunity to reduce electricity bills or receive } \\
\text { payments }\end{array}$ & & \\
\hline & * Only applicable in liberalized systems & & \\
\hline & $\begin{array}{l}{ }^{\mathrm{a}} \text { Keep frequency and voltage levels, balance active } \\
\text { and reactive power, control power factor, etc. }\end{array}$ & & \\
\hline & ${ }^{\mathrm{b}}$ Depends on the electricity mix & & \\
\hline & $\begin{array}{l}{ }^{\mathrm{c}} \text { It can be considered a benefit in systems where } \\
\text { renewable generation is encouraged }\end{array}$ & & \\
\hline
\end{tabular}

\section{Further considerations on potential benefits from demand response}

\section{Distribution of benefits among agents}

The benefits arising in generation or network activities will not necessarily be received by generation companies and network operators, respectively. The distribution of benefits among the agents is a key issue that needs to be properly assessed considering the particular regulatory framework in place when performing an economic evaluation of a DR program.

In general terms, under a centralized paradigm, the benefits would be directly transferred to consumers through lower tariffs. In liberalized systems, if there is an incentive-based remuneration scheme, benefits arising in distribution would be earned by distribution companies in the short-term, and would be transferred to customers in the long-term through lower access tariffs. On the contrary, the savings arising in the generation system would be transferred directly to customers through lower energy prices (if markets are efficient), meaning at the same time a reduction in the revenues of generation companies. In any case, a more efficient use of energy due to DR should translate into benefits for consumers (ERGEG, 2007).

According to IEA (2003), the distribution of benefits among agents in liberalized environments entails a dispersion of the incentives to undertake DR in the following way: 
- Base-load generators have little incentive and see DR only as a means of hedging to unplanned outages, whereas peaking generators view DR as direct competition.

- System operators may be interested in DR to facilitate supply and demand balance and to improve reliability.

- Network operators can use DR to relieve network congestion, improve local reliability or quality of supply or reduce network investments, but their incentives would depend crucially on their regulated remuneration scheme.

- Retailers can be interested in DR as a means to balance their contracted supply with the demand of their consumers.

- Consumers may use DR to reduce their electricity expenses, their incentives to respond basically depending on the incentives they are offered by retailers or utilities.

\section{Smart metering and other enabling technologies}

The potential benefits of DR can be broadened or amplified with the installation of enabling technologies. Indeed, most of the benefits mentioned in Table 3 can only be realized if an advanced metering and/or control infrastructure is in place. Thus, the implementation of dynamic tariffs requires an Advanced Metering Infrastructure (AMI), including the installation of "smart meters" and communication systems, and managing network contingencies through load interruptions or curtailments requires remote control devices.

In the literature, smart metering and demand response are usually related concepts. Many studies that have evaluated the cost-effectiveness of smart meters include the benefits associated to demand response in their assessment (e.g. CapGemini, 2007; Ofgem, 2006; Frontier Economics, 2006; Haney et al. 2009). In fact, the benefits of DR dominate the societal benefits that have been attributed to smart metering in recent business cases (Neenan and Hemphill, 2008). Other studies that analyze smart metering from a regulatory perspective can also provide interesting clues about demand response (e.g. EEI, 2006; ERGEG, 2007).

However, it should be noticed that the deployment of smart meters would entail some operational benefits not related to DR, such as savings in meter reading and network fault detection. These should be taken into account when performing a cost-effectiveness analysis of advanced metering infrastructures, but will not be included in this review.

Haney et al. (2009) mention the following operational benefits of smart meters:

- Improvement in the efficiency of metering services: avoided cost of meter reading, better outage detection, faster response times to outages, improved quality of supply recording and accurate billing.

- Reduction in customer service costs due to a lower level of customer complaints. 
- Non-technical losses reduction.

- Others such as greater level of choice in terms of payment options, improved consumption information or micro-generation facilitation.

Smart meters also enable detailed locational data and more efficient pricing to network users of usage and system charges (IEA, 2003: 110). Moreover, the knowledge of demand patterns that can be gained with smart metering may allow more efficient network investment and operation (just because of the value of information, even without considering DR). Finally, smart meters may provide greater scope for innovative tariffs and more competition in retailing (Frontier Economics, 2006).

There are other technologies (apart from smart meters) that can contribute to DR, such as smart thermostats (the Smart Thermostat Program is an interesting pilot in California that tested smart thermostats to control air conditioning of 5.000 residential customers (KEMA-XENERGY, 2003))., lighting control systems, under-voltage and under-frequency relays or thermal storage systems (Batlle and Rodilla, 2008). Lockheed Martin Aspen (2006) examines in detail the current status of enabling technologies for homes and small business for either reliabilitybased or price-based DR programs, and SCE (2006) presents an inventory of emerging demand response technologies.

\section{Quantitative assessment of benefits of demand response}

A proper quantitative assessment of DR benefits requires first an estimation of the changes induced in the demand, and secondly a thorough analysis of the effect of those changes on power systems. A review of studies that have approached each of these issues will be presented in the following sections.

\section{Estimating changes in demand}

Most of the benefits associated to DR programs are directly dependent on the changes in demand achieved with them. Thus, in order to evaluate DR benefits, the shifting and conservation effects in the load profiles of the participating customers need to be properly assessed. Generally, each customer segment needs to be evaluated separately to take into account differences in load patterns and in sensitivities to prices.

Notice that the level of detail in which demand changes are assessed needs to be consistent with the methodology that would be applied to estimate DR benefits. For some simple studies based on estimates, measuring variations in discrete demand blocks (e.g. on-peak and off-peak) may be sufficient, whereas complex ana- 
analyses using simulation techniques would frequently require hourly or subhourly demand patterns before and after DR.

It is also worth noticing the difficulties in predicting changes in demand. The response of consumers is uncertain and can be influenced by multiple factors, such as climate, tariff design (prices), customer type (available electric devices, incomes, level of consumption, etc.), enabling technologies, the way in which critical prices or system alerts are notified, feedback information about consumption reported to consumers, awareness and education campaigns launched, etc. (Kohler and Mitchell, 1984; Faruqui and George, 2005; Herter, 2007; EEE, 2006; Summit Blue, 2006; Darby, 2006).

Next, three different ways to approach the assessment of the effects of DR on consumption patterns will be presented: (i) using estimates from previous studies or experiences (mainly price elasticities of demand, (ii) developing an econometric demand model or (iii) simulating demand with a bottom-up model. An interesting review of methods to evaluate demand response using a different classification than the one proposed here can be found in Woo and Herter (2006).

\section{Price elasticity estimates}

Using price elasticity estimates based on previous studies or experiences is one possible and simple approach to evaluate changes in demand. The price elasticity of demand expresses the demand increment in percentage terms in response to a one percentage point increase in price.

In the context of DR, three types of elasticity are commonly used: own-price elasticity, cross-price elasticity and elasticity of substitution. Own-price elasticity expresses the demand change in one period for a $1 \%$ increment in the price of that period, whereas cross-price elasticity expresses the variation of demand in one period for a $1 \%$ increment in the price of other period (generally, between on-peak and off-peak periods). The elasticity of substitution expresses the demand shifted from on-peak periods to off-peak periods given a $1 \%$ increment in the relative price on-peak to off-peak (King and Chatterjee, 2003).

Some authors have compiled price elasticity measures observed in different types of DR programs and different regions, or have presented their own estimates. Next, Table 4 presents some elasticity values for different target customers and time-varying tariffs adapted from US DOE (2006).

Table 4: Summary of price elasticity estimates (adapted from US DOE, 2006)

\begin{tabular}{|c|c|c|c|c|}
\hline Target customers & Type of program & $\begin{array}{l}\text { Own-price } \\
\text { elasticity }\end{array}$ & $\begin{array}{l}\text { Elasticity of substitu- } \\
\text { tion }\end{array}$ & Region \\
\hline $\begin{array}{l}\text { Residential } \\
\text { (and small commer- }\end{array}$ & TOU & & $\begin{array}{l}0.07 \text { to } 0.21 \\
(0.14 \text { average })\end{array}$ & US \\
\hline
\end{tabular}




\begin{tabular}{|c|c|c|c|c|}
\hline \multirow[t]{3}{*}{ cial) } & TOU / CPP & $\begin{array}{l}-0.1 \text { to }-0.8 \\
(-0.3 \text { average })\end{array}$ & \multirow[b]{2}{*}{$\begin{array}{l}0.04 \text { to } 0.13 \\
(0.09 \text { average })\end{array}$} & US - International \\
\hline & $\mathrm{CPP}$ & & & California \\
\hline & \multirow[t]{3}{*}{ RTP } & $\begin{array}{l}-0.05 \text { to }-0.12 \\
\text { (average }-0.08 \text { ) }\end{array}$ & & Illinois \\
\hline & & -0.01 to -0.28 & & Georgia \\
\hline & & -0.01 to -0.27 & & UK \\
\hline \multirow{3}{*}{\multicolumn{2}{|c|}{$\begin{array}{l}\text { Medium or large } \\
\text { commercial and indus- RTP } \\
\text { trial }\end{array}$}} & $<-0.01$ to -0.38 & & N-S Carolina \\
\hline & & & 0.10 to 0.27 & Southwest US \\
\hline & & & $\begin{array}{l}0.02 \text { to } 0.16 \\
\text { ( } 0.11 \text { average) }\end{array}$ & New York \\
\hline
\end{tabular}

A number of studies have applied this kind of price elasticity estimates to evaluate changes in demand when assessing DR benefits. For example, Berg et al. (1983) uses hourly own-price and cross-price elasticities (both short-run and longrun values), whereas Navigant (2005) applies elasticities of substitution to compute the load shifts in the demand profile of different segments of consumers.

\section{Econometric demand models}

Econometric models try to derive the level of demand from some explicative factors based on microeconomic theory. The usual formulation is the maximization of the utility for consumers of their electricity consumption. The explicative factors most frequently used are the electricity price and the income (or budget) of the consumer. Social and demographic conditions, dwelling characteristics or technological aspects can be taken into account as well. Econometric models are developed from data of real experiences, and then used to evaluate other programs. Price-elasticity estimates are generally obtained from this type of model.

Some early examples of this approach are the studies of Lawrence and Braithwait (1979) and Hausman et al. (1979), which develop an econometric demand model to analyze the effect of TOU tariffs. In both studies, demand is given by the maximization of the consumer utility function subject to a budget constraint. Demand in different periods is considered as a different product, in such a way that load shifting can be modeled as the substitution between two products.

Similar studies analyzing TOU pricing can be found in Caves et al. (1984), Parks and Weitzel (1984) and Hill (1991). More recently, the model proposed by 
Reiss and White (2005) enables the evaluation of different tariff designs (not only TOU).

From a different perspective (and based on a real RTP experiment), Allcott (2008) estimates hourly residential demand as a utility function depending on household characteristics, daily prices and some load substitution and shifting parameters (based on temperature and dummy variables).

Econometric demand models can provide an accurate representation of the demand if the most relevant factors affecting consumption are included and the parameters expressing how demand changes with respect to those factors are properly assessed. However, since these parameters are adjusted for a given set of data under some particular conditions, econometric demand models may not be valid when the underlying conditions change. Thus, the main limitation of this type of models is that their results may be very dependent on the underlying conditions and difficult to extrapolate.

A final consideration is that econometric models that overlook the heterogeneous nature of electric loads may not be sufficiently accurate to evaluate DR actions. The utility of consumption strongly depends on its final use (the specific electric device used) and on circumstantial aspects (the service provided by the electric device in the time of consumption). Moreover, the capacity to reduce or shift demand also depends strongly on the technical potential of the electric devices in use. Therefore, including technological considerations into the demand model can improve the representation of DR actions.

\section{Bottom-up demand models}

Bottom-up demand models, unlike econometric models, aim to capture the specific loads that constitute the demand. The demand profile is obtained by aggregation of elemental loads (that may represent individual customers or the consumption of each appliance).

There are some interesting studies that have modeled electric demand using this approach but without considering any demand response action. It is the case of Cappasso et al. (1994) and Boonekamp (2007) for domestic demand. Even if these models would not be valid to evaluate DR programs, their contributions may be useful to develop models adapted to DR evaluation.

Other studies have incorporated into their bottom-up models the possibility to shift or reduce demand as a consequence of direct load control. The work of Paatero and Lund (2006) is a good example. The authors try to overcome the lack of detailed data about domestic consumption by using statistical data easily available, and incorporate stochastic processes to take into account the random nature of the demand.

Finally, some studies have considered the response of demand to prices explicitly. Conchado and Linares (2009a) suggest allocating simplified consumption cycles of electric appliances into the demand curve of individual consumers, and 
shift or reduce the consumption of each appliance according to its technical potential with the objective of minimizing the cost of consumption. In a different way, Lu et al. (2004) model thermostatically controlled loads by means of equivalent electric circuits that represent their heat transfer properties, and nonthermostatically controlled loads as tasks in a queue system.

\section{Assessing benefits}

The assessment of DR benefits can be approached from a range of possible methods, such as those based on avoided costs, resource planning, welfare analysis, value of system reliability, transmission planning and forward capacity auctions identified by Heffner (2007). The suitability of each method will depend on the type of benefit to be assessed, and there is no single approach able to capture accurately the whole range of effects of DR on power systems.

In this section, a survey of the state of the art of the quantification of DR benefits will be presented, distinguishing between two types of studies: those based on estimates and those based on simulation techniques. Both approaches have advantages and disadvantages. Studies based on estimates are simple and transparent but may fail to represent accurately the complexity of power systems. In contrast, analyses with simulation techniques allow for detailed representations of power systems but are more complicated and difficult to track back and compare.

\section{Studies based on estimates}

In this type of studies, DR benefits are derived analytically from some estimates, necessarily making simplifications about consumer and market behavior to express all relationships in algebraic terms. Generally, only a few periods (such as on-peak and off-peak) are considered for the analysis.

An illustrative example of this type of study is found in Baer et al. (2004), who evaluate the GridWise initiative in the USA. Given a set of input data (market penetration and price-elasticity of demand by end-use sector, wholesale peak and offpeak prices in a baseline scenario, projected generating reserve margin in 2025, discount rate, etc.), the system peak-load reduction is calculated. From this estimate, generation capital cost deferrals are computed by multiplying peak-load reduction by the capital cost of peaking units (gas-fired combustion turbines or diesel generators). Similarly, the operating and fuel costs associated to deferring new capacity are calculated by multiplying peak-load reduction by the fuel costs and operation and maintenance costs of the avoided peaking units. T\&D capital cost deferrals are directly estimated as a function of generation capacity deferral.

Another example of study based on estimates is a cost-benefit analysis of advanced metering in France by CapGemini (2007). Three scenarios representing 
different technology levels are considered, and it is assumed that the level of demand response depends on the technological capabilities implemented. The final estimates of benefits are allocated to generators, distributors and suppliers, which is very useful for regulatory design.

Other similar studies have been presented by Faruqui et al. (2009) for the European Union, Ofgem (2006) for the UK, Siderius and Dikstra (2006) for the Netherlands, Faruqui and George (2002) for the USA, Navigant (2005) for Ontario, or ESC (2004) for Australia.

The strong points of this approach are its simplicity and transparency. The results can be easily tracked back to the original assumptions, and it facilitates comparing the results of alternative DR designs. The drawback, however, is that it may not represent with enough level of detail the complex behavior of the market and the numerous interactions occurring in power systems. Moreover, since stochasticity is not considered (only point estimates of the parameters are used), the dependence of the results on the assumptions is magnified with respect to other methods (Neenan and Hemphill, 2008).

\section{Analyses with simulation techniques}

Instead of using estimates, DR benefits can be evaluated using models that simulate the behavior of power systems. Since simulation models allow for a detailed representation of the expansion and/or operation of generation systems and networks, or the performance of the market, this approach seems to be the most accurate for the evaluation of DR benefits.

Using simulation models, DR benefits are generally computed as the difference in the results between two simulations, one for a baseline scenario without DR and another for a scenario with DR.

Most of the studies assessing DR benefits with simulation techniques have focused on the impacts on the generation system or the wholesale market, but there are some studies addressing network impacts as well. A review of these studies is presented in this section, showing first those with focus on the generation system and wholesale market, and next those focusing on network impacts. At the end of the section, Table 5 provides a brief summary of the purpose, scope and methodology of the studies mentioned.

Impacts on the generation system and wholesale market

When modeling generation systems, whether DR is evaluated in a regulated environment or in a liberalized market affects the simulation framework. The model can be developed from the viewpoint of an utility (e.g. Berg et al., 1983) or from a market perspective, either assuming perfect competition (e.g. Borenstein, 2005) or imperfect competition (e.g. Allcott, 2008). 
DR is sometimes included endogenously into the simulation models, either by considering price-elastic demand-side bids in market equilibrium models (e.g. Su and Kirschen, 2009) or introduced as an available resource under centralized market approaches (e.g. Violette et al., 2006b). Some other studies determine the demand exogenously, either assuming certain load reductions (e.g. Brattle, 2007) or evaluating ex-ante the changes in demand (e.g. Linares and Conchado, 2009).

Some authors have analyzed DR benefits considering the stochasticity of future outcomes for key variables, as Andersen et al. (2006), who uses Monte Carlo simulations (following Violette et al., 2006b) to evaluate the potential of DR not only in average but also in extreme situations.

In order to consider network congestion, it is possible to include in the generation model a representation of the transmission network and simulate the power flow through lines. DR impacts can then be assessed by computing locational marginal prices (LMP), as done by Neenan et al. (2005) or Brattle (2007). Walawalkar et al. (2008) also use LMP in their economic welfare analysis, but compute them by means of an econometric model.

The potential of DR to facilitate real-time balancing on supply and demand in systems with large penetration of wind generation has been investigated by Sioshanshi and Short (2009) and Silva (2009). The former quantify the reduction of wind spillages if demand is elastic to real-time prices that reflect wind availability and network constraints, whereas the latter evaluates the contribution of DR to balancing considering it as a reserve resource that can be scheduled to minimize system costs.

\section{Impact on networks}

The quantification of potential impacts of DR in the network system has not been sufficiently investigated. Only a few studies have been found providing estimates of DR network benefits.

The impact of DR on the investments of distribution networks has been evaluated by Conchado and Linares (2009b) using a detailed network expansion simulation model and assuming certain reductions in the peak demand of participating customers.

Regarding network operation, the reduction in distribution losses due to domestic load-shifting has been assessed by Shaw et al. (2009), evaluating how the network power flow profiles can be changed by load-shifting and assuming that the overall potential for loss reduction is a function of the preexisting losses and the demand patterns.

A method to quantify the value of DR to alleviate network congestion has been proposed by Stanojević and Silva (2009). Using a DR model (that includes thermal load management and appliance shifting at the domestic level) integrated in a DC-OPF model allows for estimating the reduction of congestion costs due to the modification of the demand patterns. 
In a similar way, the study by Stanojević et al. (2009) shows how the modification of daily demand patterns can improve the utilization of existing network capacity by reducing network critical loading and congestion in a stressed distribution network. The model used combines the dispatch of the generation units with a multi-period optimal power flow where DR is applied to minimize the re-dispatch.

Table 5 summarizes the purpose, scope and methodology of the references mentioned throughout this section.

Table 5: Summary of the purpose, scope and methodology of the references mentioned for the quantification of DR benefits with simulation techniques

Reference Summary

Allcott, 2008

Following Borenstein (2005), evaluates the effects of RTP in the PJM market, using a two-stage model that simulates the entering of new units in the first stage and the day-ahead market in the second stage. DR is incorporated changing the slope of the demand.

Assess the short-term value of DR in the Nordic Market using the partial equilibrium model Balmorel coupled with Monte Carlo simu-

Andersen et al., 2006 lations to include extreme situations, and address market power mitigation simulating supply function equilibrium competition in the Danish system

Berg et al., 1983

Simulate the impact of TOU pricing on generation operation and expansion under a utility perspective, using price elasticities to evaluate changes in demand.

Borenstein, 2005

Evaluates the impact of RTP on long-run efficiency in a competitive electricity market with simplified simulations (representative parameters for US).

Estimates short-term impacts of day-ahead demand curtailment on locational marginal prices in the PJM market, using a model that simulates the generation dispatch together with the transmission network load flow.

In their assessment of DR benefits and costs for Spain, the authors

Conchado and Linares, 2009b analyze the impact of DR in the expansion of distribution networks by means of a model able to quantify the cost of reinforcements in real networks for expected increases in demand.

Simulate the effect of RTP (at the residential level) in the Spanish

Linares and Conchado, electricity market with a detailed generation expansion model. DR ef2009 fect on the load profile is estimated ex-ante with a bottom-up model of domestic electricity demand.

Evaluate several time-varying tariffs for large customers in New Eng-

Neenan et al., 2005 land using a prospective price formation simulation model able to compute how locational marginal prices are impacted by load changes.

Shaw et al., 2009

Provide a quantitative estimate of the possible reduction in losses associated to domestic demand shifting in Great Britain using a spreadsheet model.

Silva, 2009

Estimates the value of smart domestic appliances to reduce balancing costs in European countries with high penetration of wind generation 
by simulating the annual system operation based on simultaneous scheduling of both generation and DR, including DR as part of the standing reserve providers.

Explore how RTP prices could contribute to diminish wind spillages Sioshanshi and Short, 2009 by increasing the flexibility of demand in response to wind availability or to system constraints that limit wind generation, using a unitcommitment model with DC power-flow of the Texas power system.

Analyze the potential of DSM to mitigate network congestion, increase the utilization of network assets and avoid wind spillages by

Stanojević et al., 2009 means of a multi-period DC-OPF applied to a urban distribution network, considering historical time series data for demand and wind output.

Evaluate congestion costs in constrained electricity networks (with Stanojević and Silva, 2009 high penetration of wind generation) by incorporating DSM options (thermal load management and appliance shifting algorithms) into a DC-OPF model.

Quantify the effect of increased participation of the demand side in the electricity market using a centralized complex-bid market-

Su and Kirschen, 2009 clearing mechanism that considers the load shifting behavior of consumers who submit price-sensitive bids. Algorithm tried only in a test system.

Use a resource planning approach to assess the value of DR in a 19-

Violette et al., 2006b year horizon from an utility perspective, considering 100 Monte Carlo scenarios (case study for a region in the USA).

Perform an economic welfare analysis of DR in the PJM electricity market with a simulation of demand-side bidding, analyzing the tra-

Walawalkar et al., 2008 deoff between the distortions introduced by the subsidies provided to responsive consumers and the social welfare gains.

\section{Conclusions}

Demand response programs, usually in the context of smart grid developments, show a large potential and a promising future, particularly if the benefits that they may provide for generation systems, networks, retailers and consumers are realized. As such, they are currently being evaluated in many electricity systems across the world, either by rather simplified estimations, or by complex simulation and econometric approaches. This paper has presented a comprehensive survey of the state of the art of these assessments.

Our survey shows that the major challenges of these analysis lie in the estimation of the changes in demand profiles from these demand-response programs, and also on the assessment of the impact of these changes in demand on generation and network systems. Although many interesting studies have been identified, and given the relative infancy of these programs, much more research is needed in order to provide reliable estimates of the benefits of demand response programs, and therefore to give an rigorous indication of their interest in the short and long term. 
A first point of research should be the extension of the assessment of demand changes to many countries which are considering the implementation of demand response programs. The simple extrapolation of estimates will probably fall short of providing a reliable assessment, and therefore more pilot studies to quantify the extent and direction of changes of demand expected from DR programs would be much welcome.

Then, two major issues regarding the impact of these demand changes on the power system require more attention. First, the estimation of the benefits of these changes for network systems, both in terms of operation and investment, but particularly regarding short term emergency actions, quality of service considerations, or black starting capabilities. The assessment of the benefits for network systems is also more complicated given the dependence of these benefits on the specific regulation of the distribution companies. The second issue concerns the interaction of DR programs with intermittent generation: DR may contribute to a large extent to a stronger integration of intermittent energy sources into power systems, and therefore a careful estimation of their interaction is warranted. Again, this is not an easy task, given the non deterministic character of both DR and intermittent generation, and the sequential nature of DR actions to counteract generation deviations.

On the positive side, our survey also shows that this is a burgeoning field, with much activity in many lines of research. As such, we hope that, by identifying and categorizing them, it will provide a good starting point for many of these new inquiries.

\section{References}

Affonso, C.M., L.C.P. da Silva, W. Freitas (2006). Demand-side management to improve power security. Transmission and Distribution Conference and Exhibition, 2005/2006 IEEE PES, May.

Allcott, H. (2008). Real time pricing and imperfect competition in electricity markets. Working paper. Available from: http://economics.stanford.edu/seminars/real-time-pricing-andelectricity-markets.

Andersen, F. M., S.G. Jensen, H.V. Larsen, P. Meibom, H. Ravn, K. Skytte, M. Togeby (2006). Analyses of demand response in Denmark. Risø National Laboratory, Risø-R-1565(EN), October.

Baer, W., D. Fulton, S. Mahnowski (2004). Estimating the benefits of the GridWise initiative. Phase I report, May. Rand Science and Technology.

Batlle, C., P. Rodilla (2008). Electricity demand response tools: current status and outstanding issues. Working Paper IIT-08-006A. Prepared for: Special Issue on Incentives for a lowcarbon energy future, European Review of Energy Markets.

Berg, S.V., B.L. Capehart, J. Feldman, S. LaTour, R.L. Sullivan (1983). An interdisciplinary approach to cost/benefit analysis of innovative electric rates. Resources and Energy, 5, 313-330.

Boonekamp, P.G.M (2007). Price elasticities, policy measures and actual developments in household energy consumption - A bottom up analysis for the Netherlands. Energy Economics 29, 133-157. 
Borenstein, S. (2005). The long-run efficiency of real-time electricity pricing. The Energy Journal, 26, No. 3, 93-116.

Borenstein, S., M. Jaske, A. Rosenfeld (2002). Dynamic pricing, advanced metering and demand response in electricity markets. CSEM WP 105, University of California Energy Institute.

Braithwait, S.D., D.G. Hansen, L.D. Kirsch (2006). Incentives and rate designs for efficiency and demand response. Lawrence Berkeley National Laboratory. LBNL-60132.

Brattle Group (2007). Quantifying demand response benefits in PJM. Prepared for PJM Interconnection, LLC and the Mid-Atlantic Distributed Resources Initiative (MADRI), January.

Capasso, A., W. Grattieri, R. Lamedica, A. Prudenzi (1994). A bottom-up approach to residential load modeling. IEEE Transactions on Power Systems, 9, No.2, May, 957-964.

CapGemini (2007). Comparatif international des systèmes de télé-relève ou de télégestion et étude technico-économique visant à évaluer les conditions d'une migration du parc actuel de compteurs. March.

Caves, D.W., L.R. Christensen, P.E. Schoech (1984). A comparison of different methodologies in a case study of residential time-of-use electricity pricing - Cost-benefit analysis. Journal of Econometrics, 26, 17-34.

Conchado, A., P. Linares (2009a). Gestión activa de la demanda eléctrica: simulación de la respuesta de los consumidores domésticos a señales horarias de precio. IV Congress AEEE, Sevilla.

Conchado, A., P. Linares (2009b). Gestión activa de la demanda eléctrica doméstica: beneficios y costes. IIT Working Paper.

Crossley, D. (2008). Assessment and development of network-driven demand-side management measures. IEA Demand Side Management Programme, Task XV, Research Report No 2. NSW, Australia: Energy Futures Australia Pty Ltd.

Darby, S. (2006). The effectiveness of feedback on energy consumption: a review for DEFRA of the literature on metering, billing and direct displays. Environmental Change Institute, University of Oxford.

DTE Energy (2007). Demand response overview and pilot concepts. July.

Earle, R., E.P. Kahn, E. Macan (2009). Measuring the capacity impacts of demand response. The Electricity Journal, 22, Issue 6, 47-58.

EC (2005). Green paper on energy efficiency or doing more with less. COM (2005) 265 final. Brussels: Commission of the European Communities.

EEE (2006). A survey of Time-Of-Use (TOU) pricing and Demand-Response (DR) programs. Energy and Environmental Economics.

EEI (2006). Responding to EPAct 2005: looking at smart meters for electricity, time-based rate structures, and net metering. Washington: Edison Electricity Institute.

ERGEG (2007). Smart metering with a focus on electricity regulation. European Regulators' Group for Electricity and Gas. E07-RMF-04-03.

ESC (2004). Mandatory rollout of interval meters for electricity consumers. Final decision, July. Essential Services Commission.

Faruqui, A., S. S. George (2002). The value of dynamic pricing in mass markets. The Electricity Journal, July, 45-55.

Faruqui, A., S. S. George (2005). Quantifying customer response to dynamic pricing. The Electricity Journal, May, 53-63.

Faruqui, A., R. Hledik (2007). The state of demand response in California. Prepared for California Energy Commission, final consultant report, CEC-200-2007-003-F, September.

Faruqui, A., S. Sergici (2009). Household response to dynamic pricing of electricity - A survey of the experimental evidence. Working paper series.

Faruqui, A., D. Harris, R. Hledik (2009). Unlocking the $€ 53$ billion savings from smart meters in the EU. Discussion paper. The Brattle Group.

FERC (2006). Assessment of demand response and advanced metering. Staff report, AD-06-2000, Federal Energy Regulatory Commission. 
Frontier Economics (2006). Current prices, anybody? The costs and benefits of "smart" electricity meters.

Goldfine, D., M. Haldenstein, A. Moniz, D. Traverso (2008). Demand response review - A survey of major developments in demand response programs and initiatives. Washington: Edison Electric Institute.

Haney, A.B., T. Jamasb, M. Pollit (2009). Smart metering and electricity demand. Technology economics and international experience. Cambridge working paper in economics 0905, EPRG working paper 0903. Electricity Policy Research Group, University of Cambridge.

Hausman, J.A., M. Kinnuca, D. McFadden (1979). A two-level electricity demand model. Evaluation of the Connecticut time-of-day pricing test. Journal of Econometrics 10, 263-289.

Heffner, G. (2007). A framework for demand response valuation. Demand Response Research Center.

Herter, K. (2007). Residential implementation of critical-peak pricing of electricity. Energy Policy $35,2121-2130$.

Hill, L.J. (1991). Residential time-of-use pricing as a load management strategy. Effectiveness and applicability. Utilities Policy, July, 308-318.

Holland, S.P., E.T. Mansur (2007). Is real-time pricing green? The environmental impacts of electricity demand variance. Working paper 1350, October, National Bureau of Economic Research. Available from: http://www.nber.org/papers/w13508.

IEA (2003). The power to choose - Demand response in liberalised electricity markets. ISBN: 92-64-10503-4. OECD/International Energy Agency.

IEA (2008). World Energy Outlook. Paris: International Energy Agency.

Kärkkäinen, S., J. Ikäheimo (2009). Integration of demand side management with variable output DG. 10th IAEE European Conference, 7-10 September.

KEMA-XENERGY (2003). Smart thermostat program impact evaluation. February.

King, C.S., S. Chatterjee (2003). Predicting California demand response. Public Utilities Fortnightly, July, 27-32.

Kirschen, D. (2003). Demand-side view of electricity markets. IEEE Transactions on Power Systems, 18, May, No. 2, 520-527.

Kohler, D.F., B.M. Mitchell (1984). Response to residential time-of-use electricity rates - How transferable are the findings? Journal of Econometrics, 26, 141-177.

Lawrence, A., S. Braithwait (1979). The residential demand for electricity with time-of-day pricing. Journal of Econometrics 9, 59-7.

Linares, P., A. Conchado (2009). Gestión activa de la demanda eléctrica: Evaluación de su impacto en el sistema de generación. IV Congress AEEE, Sevilla.

Lockheed Martin Aspen (2006). Demand response enabling technologies for small-medium businesses. Technical report prepared in conjunction with the 2005 California Statewide Pricing Pilot. R.02.06.001

Lu, N., D.P. Chassin, S.E. Widergren (2004). Simulating price responsive distributed resource. Power Systems Conference and Exposition, 2004 IEE PES

Navigant Consulting (2005). Benefits of smart metering for Ontario. Discussion draft, April 5. Presented to Ontario Ministry of Energy.

Neenan B., R. Hemphill (2008). Societal benefits of smart metering investments. The Electricity Journal, 21, October, Issue 8, 32-45.

Neenan, B., P. Cappers, D. Pratt, J. Anderson (2005). Improving linkages between wholesale and retail markets through dynamic retail pricing. Prepared for New England ISO. Available at www.iso-ne.com.

NERA (2008). Cost benefit analysis of smart metering and direct load control. Overview report for consultation. Report for the Ministerial Council on Energy Smart Meter Working Group. NERA Economic Consulting.

Ofgem (2006). Domestic Metering Innovation. February.

Paatero, J.V., P.D. Lund (2006). A model for generating household electricity load profiles. Preprint version. Available from: http://users.tkk.fi/patte/pub 
Parks, R.W., D. Weitzel (1984). Measuring the consumer welfare effects of time-differentiated electricity prices. Journal of Econometrics, 26, 35-64.

PLMA (2002). Demand response: principles for regulatory guidance. Peak Load Management Alliance.

Reiss, P.C., M.W. White (2005). Household electricity demand, revisited. Review of Economic Studies, 72, 853-883.

RRI (2008). The status of U.S. demand response. Research Reports International, 7th edition.

RMI (2006). Demand response: an introduction - Overview of lessons, technologies, and lessons learned. Rocky Mountain Institute.

SCE (2006). Inventory of emerging demand response technologies. Southern California Edison.

Shaw, R., M. Attree, T. Jackson, M. Kay (2009). The value of reducing distribution losses by domestic load-shifting: a network perspective. Energy Policy, 37, 3159-3167.

Siderius, H. P., A. Dijkstra (2006). Smart metering for households: cost and benefits for the Netherlands. SenterNovem.

Silva, V. (2009). Value of smart appliances in systems balancing. Prepared for EIE project "Smart domestic appliances in sustainable energy systems" (SMART-A), WP 4.

Sioshansi, R., W. Short (2009). Evaluating the impacts of real-time pricing on the usage of wind generation. IEEE Transaction on Power Systems, 24, No. 2, May, 516-524.

Spees, K., L.B. Lave (2007). Demand response and electricity market efficiency. The Electricity Journal 20, 69-85.

Stanojević, V., V. Silva. (2009). Role of demand side management to reduce system constraints and investment. Prepared for EIE project "Smart domestic appliances in sustainable energy systems" (SMART-A), WP 4.

Stanojević, V., G. Strbac, V. Silva, P. Lang, D. Pudjianto, D. Macleman (2009). Application of storage and demand side management to optimise existing network capacity. CIRED, 20th International Conference on Electricity Distribution. Prague, 8-11 June.

Su, C., D. Kirschen (2009). Quantify the effect of demand response on electricity markets. IEEE Transactions on Power Systems, 24, August, No. 3, 1199-1207.

Summit Blue Consulting (2006). Evaluation of the 2005 Energy-Smart Pricing Plan. Summit Final report, January.

US DOE (2006). Benefits of demand response in electricity markets and recommendations for achieving them. United States Department of Energy. February.

Vasconcelos, J. (2008). Survey of regulatory and technological developments concerning smart metering in the European Union electricity market. RSCAS Policy Papers 2008/01. Florence School of Regulation.

Violette, D., R. Freeman, C. Neil (2006a). Valuation and market analyses. Volume I: Overview. Prepared for: International Energy Agency, Demand Side Programme, January.

Violette, D., R. Freeman, C. Neil (2006b). Valuation and market analyses. Volume II: Assessing the DRR benefits and costs. Prepared for: International Energy Agency, Demand Side Programme, January.

Walawalkar, R., S. Blumsack, J. Apt, S. Fernands (2008). An economic welfare analysis of demand response in the PJM electricity market. Energy Policy 36, 3692-3702.

Who, C.K., K. Herter (2006). Residential demand response evaluation: a scoping study. LBNL61090, collaborative report, Demand Response Research Center (DRCC), Ernest Orlando Lawrence Berkeley National Laboratory.

Zibelman, A., E.N. Krapels (2008). Deployment of demand response as a real-time resource in organized markets. The Electricity Journal 21, June, Issue 5, 51-56. 


\section{Acknowledgements}

This research has been funded by the GAD Project (www.proyectogad.es) and by the ADDRESS project (funded by the European Community's Seventh Framework Programme (FP7/2007-2013) under grant agreement $\mathrm{n}^{\circ}$ 207643).

The GAD (Active Demand Management) project, which is financed by the Center for Industrial Technological Development (CDTI), Spanish Ministry of Industry, Trade and Tourism, has as objective the research and development of solutions for the optimization of electricity consumption in low and middle voltage consumers. The project consortium is led by Iberdrola Distribución Eléctrica S.A, and features other 14 firms: Red Eléctrica de España, Unión Fenosa Distribución, Unión Fenosa Metra, Iberdrola, Orbis Tecnología Eléctrica, ZIV Media, DIMAT, Siemens, Fagor Electrodomésticos, BSH Electrodomésticos España, Ericsson España, GTD Sistemas de Información, Acceda Mundo Digital and Airzone. There are also other 14 research centers collaborating in the project.

Some parts of the text draw extensively from reports issued within the ADDRESS project.

Also, Financial support from the Spanish Ministry of Science and Innovation (ECO2009-14586-C02-01) is acknowledged. 